\title{
Tumor Lysis Syndrome
}

National Cancer Institute

\section{Source}

National Cancer Institute. Tumor Lysis Syndrome. NCI Thesaurus. Code C3425.

A condition of metabolic abnormalities that result from a spontaneous or therapy-related cytolysis of tumor cells. Tumor lysis syndrome typically occurs in aggressive, rapidly proliferating lymphoproliferative disorders. Burkitt lymphoma and T cell acute lymphoblastic leukemia are commonly associated with this syndrome. Metabolic abnormalities include hyperuricemia, lactic acidosis, hyperkalemia, hyperphosphatemia and hypocalcemia and may result in renal failure, multiple org an failure, and death. 